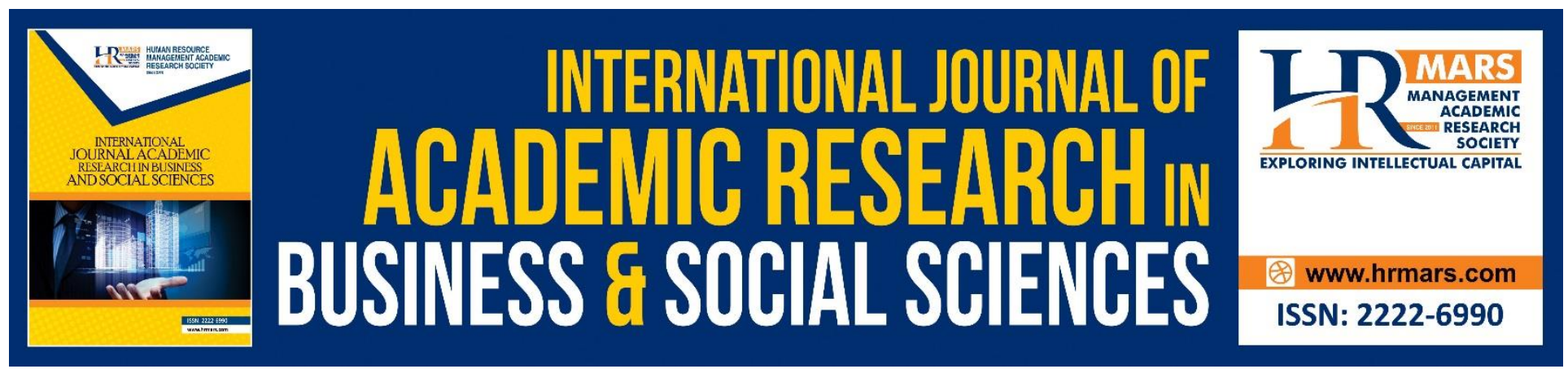

\title{
Augmenting Learning Experience in Massive Open Online Learning (MOOC)
}

Erny Arniza binti Ahmad

To Link this Article: http://dx.doi.org/10.6007/IJARBSS/v10-i10/8380

DOI:10.6007/IJARBSS/v10-i10/8380

Received: 08 November 2020, Revised: 01 December 2020, Accepted: 17 December 2020

Published Online: 29 December 2020

In-Text Citation: (Ahmad, 2020)

To Cite this Article: Ahmad, E. A. binti. (2020). Augmenting Learning Experience in Massive Open Online Learning (MOOC). International Journal of Academic Research in Business and Social Sciences, 10(10), 1201-1209.

Copyright: (C) 2020 The Author(s)

Published by Human Resource Management Academic Research Society (www.hrmars.com)

This article is published under the Creative Commons Attribution (CC BY 4.0) license. Anyone may reproduce, distribute, translate and create derivative works of this article (for both commercial and non-commercial purposes), subject to full attribution to the original publication and authors. The full terms of this license may be seen at: $\underline{\text { http://creativecommons.org/licences/by/4.0/legalcode }}$

Vol. 10, No. 10, 2020, Pg. 1201 - 1209

http://hrmars.com/index.php/pages/detail/IJARBSS

JOURNAL HOMEPAGE

Full Terms \& Conditions of access and use can be found at http://hrmars.com/index.php/pages/detail/publication-ethics 


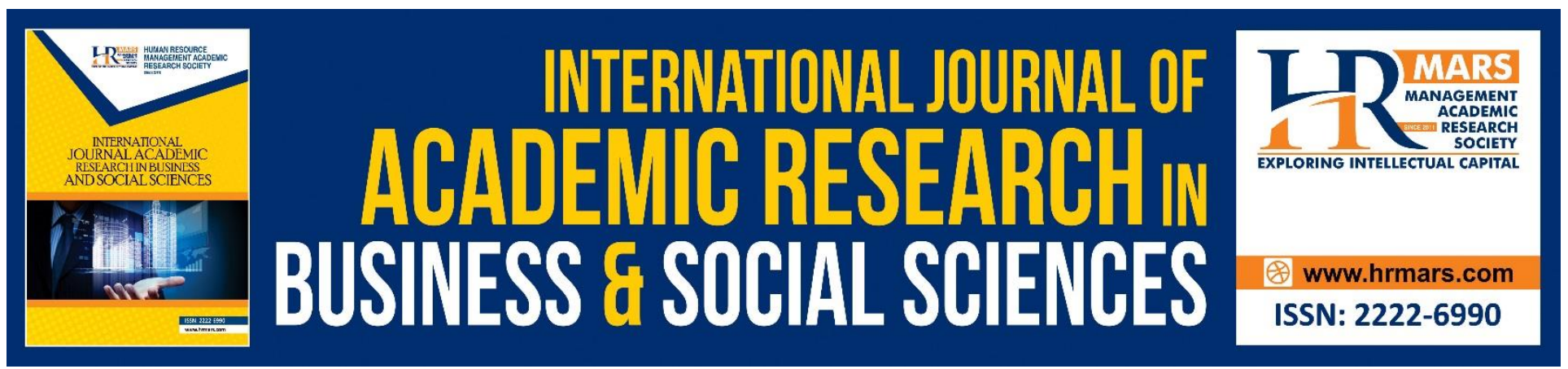

\title{
Augmenting Learning Experience in Massive Open Online Learning (MOOC)
}

\author{
Erny Arniza binti Ahmad \\ Faculty of Computer and Mathematical Sciences, Universiti Teknologi MARA Shah Alam, \\ Selangor, Malaysia \\ Email: ernie579@uitm.edu.my
}

\begin{abstract}
Massive Open Online Course (MOOC) is a new innovative way of distributing knowledge to millions of learners around the world. Despite being an excellent learning tool with global reach, MOOC has its own set of limitations, which results in incredibly low rate of course completion. Conventional techniques of content presentation are of lack personalization and interaction. For that reason, there is a need for MOOC to embrace advanced learning techniques to provide a more engaging experience to its learners. This paper explores into three techniques namely, Active Learning, Augmented Reality and Gamification. Augmented MOOC concept demonstrates the amalgamation of these techniques. It illustrates the positive impact in current learning scenario to produce interactive and more engaging content to escalate leaners motivation in completing a MOOC.
\end{abstract}

Keywords: Massive Open Online Course, MOOC, Active Learning, Augmented Reality, Gamification, Learning Techniques

\section{Introduction}

Massive Open Online Courses (MOOCs), refer to online courses taught through platforms, which seek to bring a different type of pedagogical content to various group of audience. The emergence and growth of $\mathrm{MOOC}$ has transformed the conventional model of knowledge delivery in formal education. MOOCs provide environments that enable lifelong learners to access the current information they need for both their professional and personal development without restrictions.

To date, there are many MOOC platforms have been launched. For example, Coursera, edX, and Udacity are three pioneers, followed by many others from different countries such as Openlearning and Open2Study in Australia, XuetangX in China, Khan Academy in North America, Miriada in Spain, Iversity in German, FutureLearn in England, Fun in France, Veduca in Brazil, and Schoo in Japan (Feng et al., 2019). Class Central reported that by the end of 2019, there are 13,500 courses offered worldwide by various platforms and attracted 110,000,000 online registered learners. These figures show that many institutions have invested considerable effort in MOOC development, promotion and course delivery. However, there are still unsolved issues relating to $\mathrm{MOOC}$ and their effectiveness. Few of them are accreditation and certification of learners, increased 
INTERNATIONAL JOURNAL OF ACADEMIC RESEARCH IN BUSINESS AND SOCIAL SCIENCES Vol. 10, No. 10, 2020, E-ISSN: 2222-6990 @ 2020 HRMARS

dropout rate, quality assessment of learning, personalization and individual instruction support, learner performance assessment, long-term administration and oversight, ethical and privacy issues for learner's data (Chauhan et al., 2015). Out of all these challenges, the incredibly low rate of course completion is one of the most troubling aspects (Feng et al., 2019). On average, only less than 10\% of the students complete the MOOCs they signed up for (Khalil et al., 2018). One of the identified reasons behind the scenario is due to low motivation (Ejreaw \& Drus, 2017). Therefore, better engagement techniques are required for motivating a learner to retain from sign up to course completion. This is for when learners are more motivated to learn, they are likely to better engage in learning and have a higher likelihood to complete a MOOC (Tang \& Chaw, 2019).

This paper focuses on the enhancement of MOOC by improving its content presentation techniques. Three techniques examined are Active Learning, Augmented Reality, and Gamification. These techniques have been adopted in various learning model and shown a remarkable impact on learners learning experience. Active Learning promote idea of stimulating the interaction among the participants and promote their engagement. The Augmented Reality enables interaction with real and virtual objects. The better visualization of the content keeps learners active during the learning process as it enhances human ability to understand and process information. Gamification makes sure the learners are motivated to complete the task by applying fun game elements and aesthetics to learning environment. In this study, Augmented MOOC (A-MOOC) will demonstrate the implementation of these three techniques in MOOC.

The organization of this paper is as follows. Section II discusses Active Learning, Augmented Reality and Gamification techniques in MOOC. Section III discusses the enhancement of MOOC using these techniques by representing the structure and implementation of A-MOOC. Section VI states the conclusion.

\section{Active Learning in Massive Open Online Course (MOOC)}

Engagement is promoted when active learning is emphasized and supported. Bonwell and Eison (1991) define active learning as any task or activity that involves learners in doing things and thinking about the things they are doing. It is a process whereby learners engage in learning activities that promote application, analysis, synthesis, and evaluation of new knowledge of course contents (Prince, 2004).

Instructors may facilitate active learning in MOOC using different types of teaching strategies. Among of the teaching strategies that can be employed to actively engage learners in the learning process are group discussions, problem solving, case studies, reflective scientific writing, and selfassessment. By using these strategies, instructors can motivate learners to engage in critical thinking and meaningful learning, promote retention and transfer of new information, and improved interpersonal skills with digital affordances

In the literature, Claros et al. (2014) presents several reflections about monitoring and assessment processes from two collaborative learning systems approaches and proposes some ideas about their application in a MOOC context. In addition, Kauffman \& Kauffman (2015) focused on establishing a design model embedding active learning pedagogy and instructional design concept, which includes analysing learners' background information, identifying types of content knowledge, constructing intended learning outcomes, designing interactive learning activities, and developing authentic assessments. Finally, they also provide suggestions of active learning strategies on MOOCs to facilitate the design and development of MOOCs and digital learning. Topali et al. (2019) explores 
INTERNATIONAL JOURNAL OF ACADEMIC RESEARCH IN BUSINESS AND SOCIAL SCIENCES Vol. 10, No. 10, 2020, E-ISSN: 2222-6990 @ 2020 HRMARS

the problems that learners experienced in a MOOC implementing active learning pedagogies. As the results reveal, the introduction of active learning activities can generate additional problems to learners. However, they recommended that with a careful design and a proper scaffolding at the early MOOC design and development stage may overcome the problems that will occur.

\section{Augmented Reality in Massive Open Online Course (MOOC)}

Augmented Reality (AR) refers to a concept in which real world is enhanced by blending it with virtual world. The real-world static objects are dynamically morphed with context sensitive virtual information like video, audio, or a graphic overlay to improve user's experience (Chuhan et al., 2015). The mostly cited advantages of AR included encouraging motivation, comprehension and involvement of learners, and reducing learners' cognitive load.

The conventional instruction delivery methods for MOOCs include recorded videos, lecture slides, discussion boards and web-based collaboration tools. These methods provide basic collaboration among learners but learner engagement with other learners or course participation is low. Immersive environments created using augmented reality provide a collaborative environment by creating a shared space between learners, which renders a more engaging experience for learners (Chuhan et al., 2015).

There has been a pilot project to teach Structural Reading at Georgia Tech using Augmented Panorama technology to learners through a MOOC course. Panoramas provide a natural and intuitive experience that simulates the real environment for users where locations and location-specific information are of interest to the user (Geisari et al., 2015). Another attempt of learner learning enhancement was tried with marker-based augmented reality; a generic framework was developed so that academics can upload relevant AR models for the course (Gunatunge et al., 2014). Fauzi et al. (2018) proposed The Augmented Biodiversity Lab, which aimed to amalgamate entertainment and study by providing immersive learning experience to learners in Biodiversity MOOC. Through the Augmented Biodiversity Lab, several Augment Reality applications are used to enable the learners to explore and discover the intricate anatomical details of selected fauna and flora. Their expectation with this enhancement is to impart a great deal of knowledge and better learning outcomes for Biodiversity MOOC (Fauzi et al., 2018)

\section{Gamification in Massive Open Online Course (MOOC)}

Gamification is defined as the application of game elements in traditionally non-recreational contexts with the purpose of making an impact and solving problems. Commonly, the elements used in gamification in education are points, badges, and leaderboards, although awards, acknowledgments, levels, and feedback are also persistent (Rughini et al., 2019),

In relation to the effectiveness of using gamification in MOOCs, Zichermann and Cunningham (2011) demonstrated that the factors of gamified designs in this educational modality increased social engagement by providing fun, interactive, and significant experiences for participants, resulting in more unique visitors per day and longer average connection time in activities. Rughiniş (2013), who explains that applying gamification in e-learning contexts increases productive interactivity for certain types of participants, also shares this perspective. Chang and Wei (2016), in contrast, identified 40 typologies of gamification mechanics in MOOCs from Coursera, Udacity, and edX, verifying that their transversal inclusion in course activities and challenges increased learner immersion and commitment toward gamified content. An empirical study by Vaibhav and Gupta 
INTERNATIONAL JOURNAL OF ACADEMIC RESEARCH IN BUSINESS AND SOCIAL SCIENCES Vol. 10, No. 10, 2020, E-ISSN: 2222-6990 @ 2020 HRMARS

(2014) examined the use of gamification in a MOOC through an A/B testing planned task. The researchers found out that the gamified quiz attracted a larger number of learners than those without gamification in regard to the number of quizzes learner submitted. Additionally, they also realized that the success rate of the quizzes was higher for the cohort who were supported with gamification and therefore recorded a slight increased retention in comparison to the control group.

\section{Augmented Massive Open Online Course (A-MOOC)}

Augmented Massive Open Online Course (A-MOOC) is a concept, which explores three different learning techniques implementation in MOOC. The word "augmented" in this study is referring to the enhancement of $\mathrm{MOOC}$ learning experience by increasing learner's engagement and motivation using different learning techniques. Figure 1 shows the structure of A-MOOC.

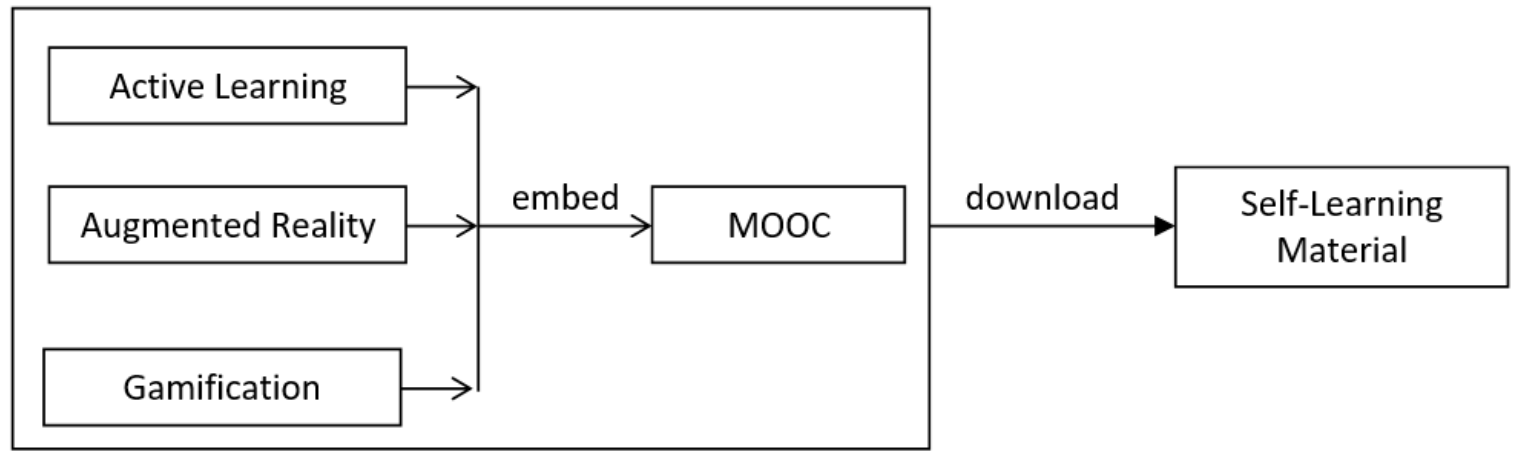

Figure 1. A-MOOC Structure

Active Learning, Augmented Reality and Gamification techniques were applied to the entire content design of the MOOC. The additional feature of A-MOOC is where every learning activities (Figure 2.) of the MOOC are downloadable and printable. This will allow the learners to continue their MOOC learning activities in an offline mode. The rest of the sections will detail out the implementation of these techniques.

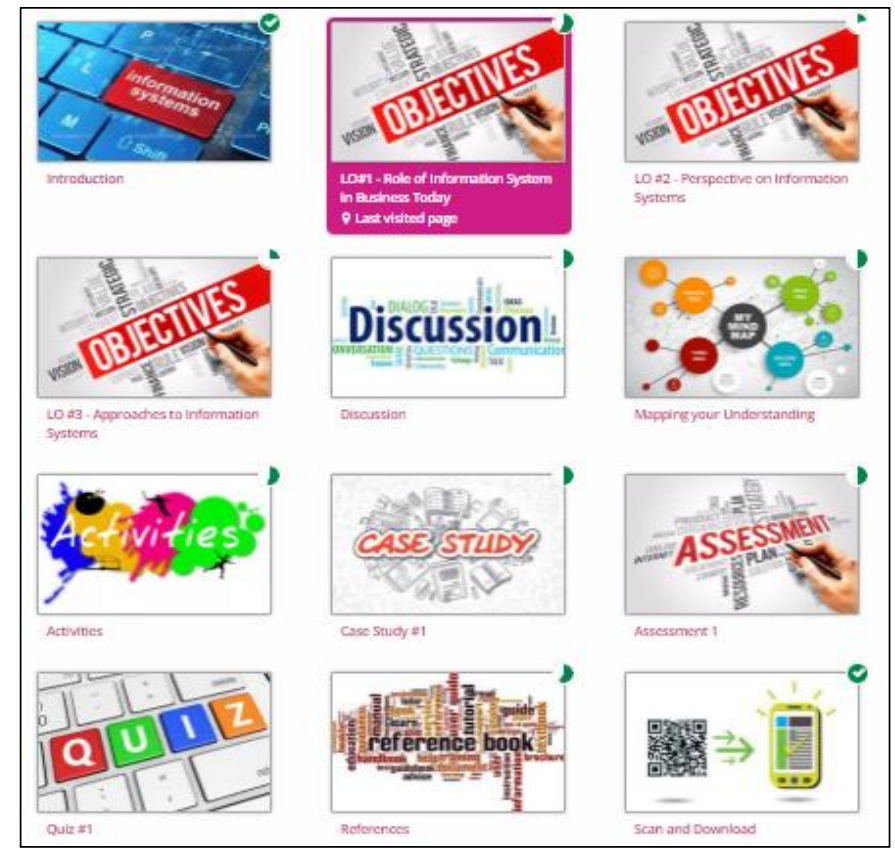


INTERNATIONAL JOURNAL OF ACADEMIC RESEARCH IN BUSINESS AND SOCIAL SCIENCES Vol. 10, No. 10, 2020, E-ISSN: 2222-6990 @ 2020 HRMARS

\section{Active Learning in A-MOOC}

The core elements of active learning are learner activity and engagement in the learning process (Prince, 2004). There are different types of learning activities provided in MOOC. The main activity is to understand the concept of the course offered. These main concepts are explained in the learning videos, which created based on video design-related strategies. The strategies include using "bite-size" videos that cover usually the main concepts or learning objectives. By using optional subtitles on video, it helps learners to follow the presentation of materials. Learning videos are also downloadable to avoid potential online stall or crash. By doing so, learners will be able to vary the speed of the video presentations. Besides that, slides or notes that summarize the main concepts covered also provided. This is to assist the learners further in their learning process.

A-MOOC also provides activities that required learners to apply what they had learned. For example, MindMapping, Fun Activities, and Case Study. The continuous activities will help the learners to understand the course better. Instead of that, A-MOOC also employed computer graded quizzes that provided immediate feedback. Effective quizzes do not merely test recall. Unlike some other MOOCs, the quizzes used in A-MOOC mostly assessed the following types of cognitive processes: understanding, analyzing, applying and evaluating. The purpose of these activities and quizzes is to help learners review the course content.

\section{Augmented Reality in A-MOOC}

Augmented Reality (AR) is transforming the learning environment by enhancing learner's real environment with virtual information. The overlaid information is hidden under the cues which when scanned with AR enabled devices bring static environment to life and provides better learning experience for learners. AR consists of adding links to pictures, videos, or text onto the image of some real object on the screen of a computer or smartphone. There are various ways to trigger the augmented reality connection, but a QR (Quick Response) code is the simplest and probably the most often used. A-MOOC utilized both Quick Response (QR) code and 3DQR code. 3DQR code is an application specifically design to view $A R$ by using a QR code (https://3dqr.de/). The learning videos in augmented reality form are linked to the 3DQR code and the learner can scan the 3DQR code to watch the videos in $A R$ or $3 D$ view. MOOC learners can utilize mobile devices and wearables to experience the AR world. While, the rest of learning activities are linked the QR code. This method will create an immersive learning environment for the learners, also add more fun, and thus, provide better engagement.

\section{Gamification in A-MOOC}

Learning process can be gamified to motivate learners and engage them in better way. There are a several gamification elements that can be rewarding, for instance, ranking, course progress, levels and certification. To embed gamification in MOOC, the challenge is to apply the right gamification components in the most effective way. There are several ways where A-MOOC applied the Gamification elements.

Ranking in A-MOOC shows the learners rank for each quiz and the whole course. A progress bar displays every learner's progress and status, where they can see the activities they have done and the activities that are still pending for action. Instead of having a lengthy content with no middle goals, levels provide smaller sections of the course content. Each level must be completed in order to unlock the next level. Levels typically begin with easy content and activities and will progress to 
more difficult activities with every successfully unlocked level. Every completed level will give a sense of accomplishment to learners. Learner will be rewarded with points and badges for every level they have completed. This will encourage them to learn more. For certification purposes, learner will be awarded with Certification of Completion once they have completed the course.

\section{A-MOOC Self-Learning Materials}

A World Health Organization report entitled "Availability and utilization of self-learning materials in continuing education" defines self-learning materials (SLM) as "any learning resource that can be used by a learner without the physical presence of a teacher". A Self-learning material itself performed the functions of an effective classroom teacher by providing learning experiences similar to the classroom-based teaching-learning process. Thus, the invisible teacher built in the learning materials facilitates the learners in their studies in the same way as the classroom teacher does within the face-to-face classes: To support the SLM functions, A-MOOC allows learner to download and print the MOOC materials (Figure 3.). The SLM comprise of course notes and selfinstructed learning activities. Instead of completing the MOOC learning activities online, learners may opt to complete all the activities offline. Learners may use A-MOOC SLM when there is no internet connection available. The internet connection is only necessary when the learner wants to view the learning videos and to submit the activities to MOOC. A-MOOC offers flexibility to the learner for them to learn at their own preferences, at anytime, anywhere and anyway.

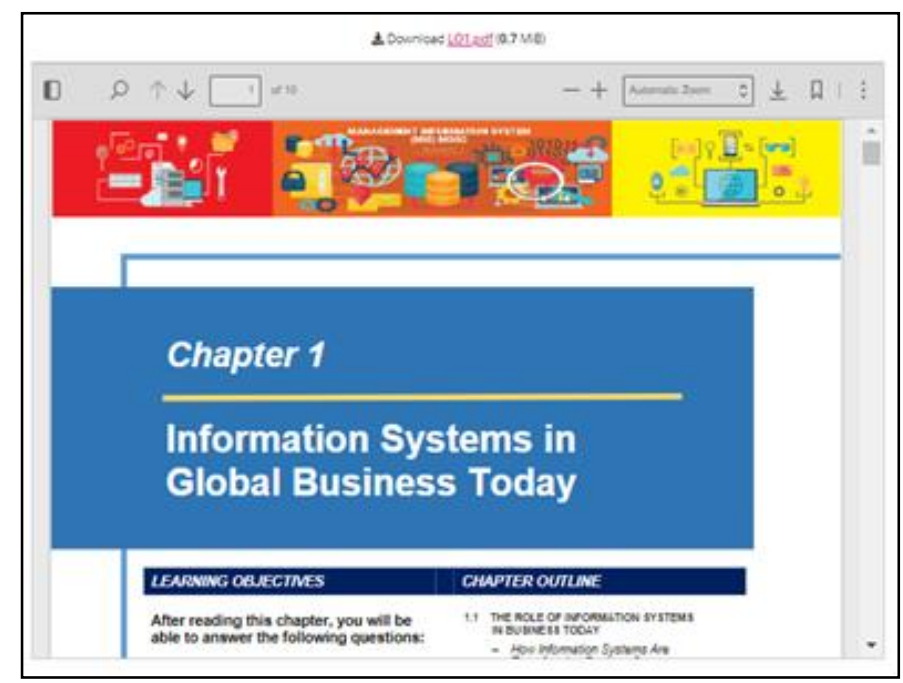

Figure 2.0: Self-Learning Materials Download Section

\section{Conclusion}

The use of Active Learning, Augmented Reality, and Gamification provides favorable environment for the learners that enhances learning outcomes by engaging them during the learning process. Stimulating the interaction among the participants, enabling interaction between real and virtual objects to provide better content visualization and applying fun elements and aesthetics to learning environment are some of the key factors of these techniques. The study blends these techniques together with $\mathrm{MOOC}$ content to provide an enriched environment. This enriched MOOC learning environment is knowns as Augmented MOOC (A-MOOC). A-MOOC demonstrate how these 
INTERNATIONAL JOURNAL OF ACADEMIC RESEARCH IN BUSINESS AND SOCIAL SCIENCES

Vol. 10, No. 10, 2020, E-ISSN: 2222-6990 @ 2020 HRMARS

techniques were blend in an online and offline mode. The expectation with this amalgamation is to improve learner engagement that eventually motivate them to complete the course.

\section{Corresponding Author}

Erny Arniza binti Ahmad

Faculty of Computer and Mathematical Sciences,

Universiti Teknologi MARA (UiTM),

40450, Shah Alam, Selangor, Malaysia

Email: ernie579@uitm.edu.my

\section{References}

Bonwell, C. C., \& Eison, J. A. (1991). Active Learning: Creating Excitement in the Classroom. 1991 ASHE-ERIC Higher Education Reports. ERIC Clearinghouse on Higher Education, The George Washington University, One Dupont Circle, Suite 630, Washington, DC 20036-1183.

Chang, J. W., and Wei, H. Y. (2016). Exploring Engaging Gamification Mechanics in Massive Online Open Courses. Educational Technology \& Society, 19(2), 177-203.

Chauhan, J., Taneja, S., \& Goel, A. (2015). Enhancing MOOC with augmented reality, adaptive learning and gamification. In 2015 IEEE 3rd International Conference on MOOCs, Innovation and Technology in Education (MITE) (pp. 348-353). IEEE.

Claros, I., Garmendia, A., Echeverria, L., \& Cobos, R. (2014). Towards a collaborative pedagogical model in MOOCs. In 2014 IEEE Global Engineering Education Conference (EDUCON) (pp. 905911). IEEE.

Fauzi, N., Arumugam, N., \& Ibrahim, N. (2018). TOPIC: Amalgamation of Augmented Reality with MOOC in Learning Biodiversity. University Carnival on E-Learning (IUCEL) 2018, 237.

Feng, W., Tang, J., \& Liu, T. X. (2019, July). Understanding dropouts in MOOCs. In Proceedings of the AAAl Conference on Artificial Intelligence (Vol. 33, pp. 517-524).

Gheisari, M., Sehat, N., \& Williams, G. (2015). Using augmented panoramic views as an online course delivery mechanism in MOOCs. In 51st ASC annual international conference proceedings (pp. 291-297).

Gunatunge, E. M. P., Hewagama, H. Y. M., Hewawalpita, S. G. S., Perera, I., \& Udara, Y. B. N. (2014). AugLAC-Generic framework for augmented location aware commerce. In 7th International Conference on Information and Automation for Sustainability (pp. 1-5). IEEE.

Hew, K. F. (2016). Promoting engagement in online courses: What strategies can we learn from three highly rated MOOCS. British Journal of Educational Technology, 47(2), 320-341.

Kauffman, Y., \& Kauffman, D. (2015, June). MOOCs design and development: Using active learning pedagogy and instructional design model in MITx courses on the edX platform. In EdMedia+ Innovate Learning (pp. 22-27). Association for the Advancement of Computing in Education (AACE).

Khalil, M., Wong, J., de Koning, B., Ebner, M., \& Paas, F. (2018). Gamification in MOOCs: A Review of the State of the Art. In 2018 IEEE Global Engineering Education Conference (EDUCON) (pp. 16291638). IEEE.

Prince, M. (2004). Does active learning work? A review of the research. Journal of engineering education, 93(3), 223-231. 
INTERNATIONAL JOURNAL OF ACADEMIC RESEARCH IN BUSINESS AND SOCIAL SCIENCES

Vol. 10, No. 10, 2020, E-ISSN: 2222-6990 @ 2020 HRMARS

Romero-Rodriguez, L. M., Ramírez-Montoya, M. S., \& González, J. R. V. (2019). Gamification in MOOCs: Engagement application test in energy sustainability courses. IEEE Access, 7, 3209332101.

Romero-Rodriguez, L. M., Ramirez-Montoya, M. S., \& Gonzalez, J. R. V. (2019). Gamification in MOOCs: Engagement application test in energy sustainability courses. IEEE Access, 7, 3209332101.

Rughiniş, R. (2013). Gamification for productive interaction: Reading and working with the gamification debate in education. In 2013 8th Iberian Conference on Information Systems and Technologies (CISTI) (pp. 1-5). IEEE.

Tang, C. M., \& Chaw, L. (2019). Driving high inclination to complete massive open online courses (MOOCS): motivation and engagement factors for learners. Electronic Journal of e-Learning, 17, 118-130.

Topali, P., Ortega-Arranz, A., Er, E., Martínez-Monés, A., Villagrá-Sobrino, S. L., \& Dimitriadis, Y. (2019, May). Exploring the problems experienced by learners in a MOOC implementing active learning pedagogies. In European MOOCs Stakeholders Summit (pp. 81-90). Springer, Cham.

Vaibhav, A., and Gupta, P. (2014). Gamification of MOOCs for increasing user engagement. In 2014 IEEE International Conference on MOOC, Innovation and Technology in Education (MITE), (pp. 290-295). IEEE.

Zichermann, G., \& Cunningham, C. (2011). Gamification by design: Implementing game mechanics in web and mobile apps. " O'Reilly Media, Inc.". 